\title{
Combined Brown syndrome and superior oblique palsy without a trochlear nerve: case report
}

\author{
Hee Kyung Yang ${ }^{1 \dagger}$, Jae Hyoung $\mathrm{Kim}^{2+}$, Ji-Soo Kim³ and Jeong-Min Hwang ${ }^{{ }^{*}}$
}

\begin{abstract}
Background: Congenital Brown syndrome is characterized by limited elevation particularly during adduction. The pathogenesis of congenital Brown syndrome is still controversial.

Case presentation: A 6-year-old boy had been tilting his head to the left since infancy. He showed right hypertropia (RHT) of 2 prism diopters $(\Delta)$ in the primary position. He showed RHT $6 \Delta$ in right gaze, RHT $2 \Delta$ in left gaze, RHT $12 \Delta$ in right head tilt, and orthotropia in left head tilt. The right eye showed limitation of elevation and depression on adduction, and the left eye showed overdepression on adduction. MR images showed an absent right trochlear nerve with a hypoplastic ipsilateral superior oblique muscle.
\end{abstract}

Conclusions: Congenital Brown syndrome may be associated with an absent trochlear nerve and hypoplastic superior oblique muscle suggesting an etiologic mechanism of congenital cranial dysinnervation disorder.

Keywords: Brown syndrome, Superior oblique palsy, Trochlear nerve

\section{Background}

Congenital Brown syndrome is characterized by limited elevation particularly during adduction from mechanical causes [1]. The pathogenesis of congenital Brown syndrome is still controversial, and we have previously found normal-sized trochlear nerves and superior oblique (SO) muscles on high-resolution magnetic resonance imaging (MRI) in nine patients with congenital Brown syndrome [2]. In contrast, Kaeser et al. reported an absent trochlear nerve with normal sized SO muscles [3], and Ellis et al., a hypoplastic SO in congenital Brown syndrome without confirming the status of the trochlear nerve, suggesting the etiology as a variant of congenital cranial dysinnervation disorders (CCDD) [4]. Recently we found a patient with limited elevation and depression during adduction suggesting congenital Brown syndrome with concurrent SO palsy in the same eye, who had no

\footnotetext{
* Correspondence: hjm@snu.ac.kr

${ }^{\dagger}$ Equal contributors

'Department of Ophthalmology, Seoul National University College of Medicine, Seoul National University Bundang Hospital, 166, Gumiro,

Bundang-gu, Seongnam, Gyeonggi-do 463-707, South Korea

Full list of author information is available at the end of the article
}

visible trochlear nerve on the ipsilateral side together with a hypoplastic SO confirmed by high-resolution MRI.

\section{Case presentation}

A 6-year-old had been tilting his head to the left since infancy. His past medical history was unremarkable. Best-corrected visual acuities were 20/30 in both eyes. He showed right hypertropia (RHT) of 2 prism diopters $(\Delta)$ on alternate prism and cover test in the primary position at distance and at near. He showed RHT $6 \Delta$ in right gaze, RHT $2 \Delta$ in left gaze, RHT $12 \Delta$ in right head tilt, and orthotropia in left head tilt. The right eye showed limited elevation $(-3)$ and depression $(-4)$ on adduction, and the left eye showed overdepression $(+3)$ on adduction. The right eye also showed mild limitation of elevation ( -1$)$ on abduction causing an overelevation $(+1)$ on adduction in the contralateral left eye. Widening of the lid fissure was found during adduction and elevation in the right eye, and this was not found in the left eye (Fig. 1a). There was no subjective torsion measured with the double Maddox rod test. Fundus photographs with an internal fixator featured 3 degrees of extorsion in the right eye and no torsional abnormality in the left eye. Forced duction test revealed a mild restriction 


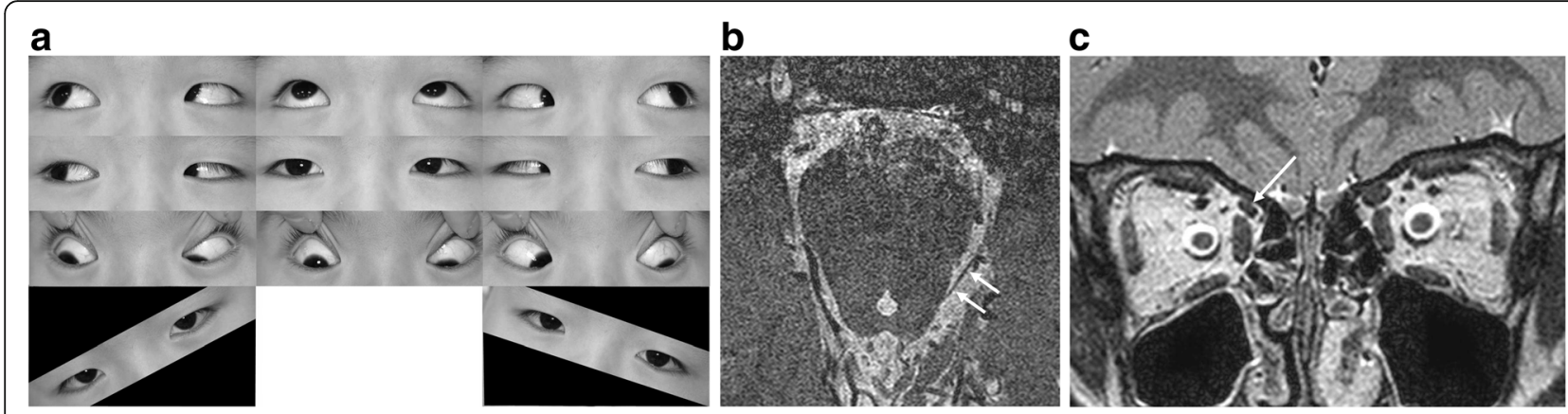

Fig. 1 a Ocular versions demonstrating limitation of elevation and depression on adduction and downgaze of the right eye, and overdepression on adduction of the left eye. During adduction and elevation, widening of the lid fissure is clearly distinct in the right eye compared to the left eye. $\mathbf{b}$ The left trochlear nerve (arrows) is well identified, but the right is not observed. c The right superior oblique muscle is hypoplastic (arrow) compared to the left

during adduction and elevation in the right eye. Saccadic velocities measured with infrared video-oculography were within normal ranges and symmetric in both eyes in the horizontal, vertical and diagonal directions.

T2-weighted images were obtained with $0.25-\mathrm{mm}$ thickness for the trochlear nerve, and 1.4-mm thickness for the oculomotor nerve and abducens nerve in the basal cistern using a 3-Tesla MRI system (Intera Achieva; Philips Healthcare, Best, the Netherlands). The right trochlear nerve was absent, and ipsilateral SO muscle was hypoplastic (Figs. 1b, c). The oculomotor and abducens nerves were of normal size on both sides. All the other extraocular muscles except the SO were normal in size and symmetric on both sides. The distance between the annulus of Zinn and the trochlea was $31 \mathrm{~mm}$ in both eyes.

\section{Discussion}

In this report, we clearly showed that the right trochlear nerve was absent and ipsilateral SO muscle was hypoplastic, thus supporting that CCDD is one of the etiologic mechanisms of Brown syndrome.

Kaeser et al. [3] first reported the association of congenital Brown syndrome and an absent trochlear nerve. They reported bilaterally absent trochlear nerves in two patients and a unilaterally absent trochlear nerve in two other patients [3]. Interestingly, the SO was not hypoplastic in any of their four patients suggesting the possibility of an alternative innervation [3]. However, they used a 1.5-Tesla magnetic resonance unit (Siemens, Erlangen, Germany) [3], and in our experience, the trochlear nerve was visible only by using a voxel smaller than the diameter of the trochlear nerve in a highresolution 3-Tesla system [5]. In our previous studies on congenital superior oblique palsy, all the patients without a trochlear nerve were unilaterally affected [5-9], and their paretic SO areas and volumes were significantly smaller than the normal side [9]. In contrast, in patients with a normal trochlear nerve, the paretic SO areas and volume showed no significant difference with the normal side [9]. Therefore, it is unlikely to observe a normal-sized SO in any patient without a trochlear nerve, particularly if the SO palsy is congenital. The possibility of synkinesis may arise in such conditions with a normal-sized SO and absent trochlear nerve, [3] however, the size of the SO may still be smaller than the contralateral normal side as found in our case.

The pathologic findings that have been found in Brown syndrome include enlarged and irregular tendon-trochlea complex [10], hypoplasia of the paretic SO $[4,11]$, restrictive fibrous adhesions to the posterior globe [12], increase of the distance between the annulus of Zinn and the trochlea [13], and bifid scleral insertion of SO [14]. Our patient showed hypoplasia of the paretic SO and an absent trochlear nerve, however, he also showed minimal extorsion in the paretic eye, and widening of the lid fissure during ipsilateral adduction and elevation, which are all indirect signs of an anomalous innervation of the SO muscle by fibers of the oculomotor nerve originally innervating the inferior oblique (IO) muscle [15]. Simultaneous contraction of the $\mathrm{SO}$ with $\mathrm{IO}$ muscles might produce limitation of elevation in adduction and minimal extorsion, or even intorsion [15]. The more anomalous branches of the IO supplying oculomotor nerve misdirected to the $\mathrm{SO}$, the more intorsion might be induced. However, to date, direct evidence of synkinetic innervation of the SO muscle by branches of the oculomotor nerve has not been obtained histologically or with electromyography [15].

Brown syndrome could be classified as mild (no hypotropia in primary or adducted position), moderate (hypotropia in adducted position), and severe (hypotropia in primary position) [16]. Jampolsky classified Brown syndrome as true Brown syndrome (no hypotropia in primary position or down gaze) and Brown syndrome plus (vertical deviation in primary position or adduction with/without head posture) [17]. With written and oral 
communications, Stager et al. [18] termed Brown syndrome plus as Brown syndrome worse than mild Brown syndrome, which showed no vertical deviation in any of the horizontal gaze positions. Our patient corresponded to mild or true Brown syndrome because he showed a right hypertropia of $2 \Delta$ in the primary position. Forced duction test revealed a mild restriction in the field of action of the right SO. In addition, he also showed a mild limitation of elevation during abduction, which also could be helpful to rule out the possibility of a right IO palsy. An anomalous innervation of the SO muscle by fibers of the oculomotor nerve originally innervating the IO muscle may simulate Brown syndrome showing a positive forced duction test.

Our patient showed not only Brown syndrome, but also superior oblique palsy mimicking canine tooth syndrome or dog-bite syndrome. Canine tooth syndrome is an ocular motility disorder characterized by limited elevation and depression on adduction [19]. Canine tooth syndrome is originally reported with a dog bite of the superior oblique trochlea region, but subsequently with head injury [20], superior oblique myocysticercosis [21], iatrogenic injury to the superior oblique tendon such as sinus surgery [22] or hook injury [23]. Our patient did not have any history of injury or infection, and proved the possibility of trochlear nerve agenesis as the etiology of canine tooth syndrome.

CCDD represent a group of neurodevelopmental diseases of the brainstem and cranial nerves [4]. As Ellis et al. assumed from their three patients with SO hypoplasia [4], one of the etiologic mechanisms of Brown syndrome may include CCDDs caused by an absent trochlear nerve. However, the underlying etiologies remain unknown in most of the cases and are yet to be elucidated. The positive forced duction test and spontaneous resolution found in some cases suggest that innervational and structural mechanisms may both be responsible for this phenomenon [16].

\section{Conclusion}

Congenital Brown syndrome may be associated with an absent trochlear nerve and SO hypoplasia suggesting an etiologic mechanism of CCDD.

\footnotetext{
Abbreviations

CCDD: congenital cranial dysinnervation disorder; MRI: magnetic resonance imaging; RHT: right hypertropia; SO: superior oblique
}

\section{Acknowledgments \\ None.}

\section{Availability of data and materials}

Data for this case report were collected by chart review of the patient's electronic medical record, which is not publicly available due to privacy considerations.

\section{Authors' contributions}

Collection of data (YHK, KJH, KJS, HJM), preparation of the manuscript (YHK, $\mathrm{KJH}, \mathrm{KJS}, \mathrm{HJM})$ and supervision (YHK, KJH, KJS, HJM) were carried out. All authors read and approved the final manuscript.

\section{Ethics approval and consent to participate}

Not applicable.

\section{Consent for publication}

Informed written consent to publish data and images was obtained from the mother described in this case report.

\section{Competing interests}

Authors do not have any competing interests in the publication of this case report.

\section{Publisher's Note}

Springer Nature remains neutral with regard to jurisdictional claims in published maps and institutional affiliations.

\section{Author details}

'Department of Ophthalmology, Seoul National University College of Medicine, Seoul National University Bundang Hospital, 166, Gumiro, Bundang-gu, Seongnam, Gyeonggi-do 463-707, South Korea. ${ }^{2}$ Department of Radiology, Seoul National University College of Medicine, Seoul National University Bundang Hospital, Seongnam, South Korea. ${ }^{3}$ Department of Neurology, Seoul National University College of Medicine, Seoul National University Bundang Hospital, Seongnam, South Korea.

Received: 23 November 2016 Accepted: 17 August 2017

Published online: 25 August 2017

\section{References}

1. Brown HW. True and simulated superior oblique tendon sheath syndrome. Doc Ophthalmol. 1973;34:123-36.

2. Kim JH, Hwang JM. Magnetic resonance imaging in congenital Brown syndrome. Graefes Arch Clin Exp Ophthalmol. 2015;253:1385-9.

3. Kaeser PF, Kress B, Rohde S, Kolling G. Absence of the fourth cranial nerve in congenital Brown syndrome. Acta Ophthalmol. 2012;90:e310-3.

4. Ellis FJ, Jeffery AR, Seidman DJ, Sprague JB, Coussens T, Schuller J. Possible association of congenital Brown syndrome with congenital cranial dysinnervation disorders. J AAPOS. 2012;16:558-64.

5. Choi BS, Kim JH, Jung C, Hwang JM. High-resolution 3D MR imaging of the trochlear nerve. AJNR Am J Neuroradiol. 2010;31:1076-9.

6. Kim JH, Hwang JM. Absence of the trochlear nerve in patients with superior oblique hypoplasia. Ophthalmology. 2010;117:2208-13.

7. Yang HK, Kim JH, Hwang JM. Congenital superior oblique palsy and trochlear nerve absence: a clinical and radiological study. Ophthalmology. 2012;119:170-8.

8. Lee DS, Yang HK, Kim JH, Hwang JM. Morphometry of the trochlear nerve and superior oblique muscle volume in congenital superior oblique palsy. Invest Ophthalmol Vis Sci. 2014;55:8571-5.

9. Yang HK, Lee DS, Kim JH, Hwang JM. Association of superior oblique muscle volumes with the presence or absence of the trochlear nerve on high-resolution MR imaging in congenital superior oblique palsy. AJNR Am J Neuroradiol. 2015;36:774-8

10. Sener EC, Ozkan SB, Aribal ME, Sanac AS, Aslan B. Evaluation of congenital Brown's syndrome with magnetic resonance imaging. Eye (Lond). 1996;10: 492-6.

11. Suh SY, Le A, Demer JL. Size of the oblique extraocular muscles and superior oblique muscle contractility in Brown syndrome. Invest Ophthalmol Vis Sci. 2015:56:6114-20.

12. Bhola R, Rosenbaum AL, Ortube MC, Demer JL. High resolution magnetic resonance imaging demonstrates varied anatomic abnormalities in Brown syndrome. J AAPOS. 2005;9:438-48. 
13. Abrams MS. A new mechanism for Brown's syndrome. J Pediatr Ophthalmol Strabismus. 2009;46:115-7.

14. Park SW, Heo H, Park YG. Brown syndrome with bifid scleral insertion of the superior oblique. J Pediatr Ophthalmol Strabismus. 2009;46:171-2.

15. Kaeser P-F, Brodsky MC. Fourth cranial nerve palsy and Brown syndrome: two interrelated congenital cranial dysinnervation disorders? Curr Neurol Neurosci Rep. 2013;13:352.

16. Murthy R. Brown syndrome. Kerala J Ophthalmol. 2009;21:186-9.

17. Jamposky A. Discussion of Wilson ME, Sinatra RB, Saunders RA. Downgaze restriction after placement of superior oblique tendon spacer for Brown syndrome. J Pediatr Ophthalmol Strabismus. 1995:32:35-6.

18. Stager DR Jr, Parks MM, Stager DR Sr, Pesheva M. Long-term results of silicone expander for moderate and severe Brown syndrome (Brown syndrome "plus"). J AAPOS. 1999;3:328-32.

19. Knapp P. Classification and treatment of superior oblique palsy. Am Orthopt J. 1974;24:18-22

20. Rowe F, Ramasamy B, Noonan C. Canine tooth syndrome following occipital impact closed head injury. Neuro-Ophthalmology. 2007;31:23-7.

21. Pandey PK, Bhatia A, Garg D, Singh R. Canine tooth syndrome due to superior oblique myocysticercosis. J Pediatr Ophthalmol Strabismus. 2006; 43:185-7.

22. Rosenbaum AL, Astle WF. Superior oblique and inferior rectus muscle injury following frontal and intranasal sinus surgery. J Pediatr Ophthalmol Strabismus. 1985;22:194-202.

23. Wright KW. Brown's syndrome: diagnosis and management. Trans Am Ophthalmol Soc. 1999;97:1023-109.

\section{Submit your next manuscript to BioMed Central} and we will help you at every step:

- We accept pre-submission inquiries

- Our selector tool helps you to find the most relevant journal

- We provide round the clock customer support

- Convenient online submission

- Thorough peer review

- Inclusion in PubMed and all major indexing services

- Maximum visibility for your research

Submit your manuscript at www.biomedcentral.com/submit 